AC 2012-5071: IMPORTANCE OF ADVISORY BOARDS IN PROGRAM DEVELOPMENT AND MANAGEMENT

Dr. Shekar Viswanathan, National University

Shekar Viswanathan is the Chair and professor of the Applied Engineering Department at National University. He has more than 30 years of academic and industry experience. 


\title{
Importance of Advisory Boards in Program Development and Management
}

\begin{abstract}
Developing and managing technical academic programs, successfully, has become increasingly challenging in today's fast-paced global environment. In part to help meet these challenges, many engineering colleges and departments are utilizing advisory boards, and these boards of external advisors are becoming an important part of most academic institutions.
\end{abstract}

NU's School of Engineering, Technology and Media (SETM), since its inception in 2002, has organized and used advisory boards to guide the development and ongoing management of its programs. In addition to assisting in design and development of curricula and in specifying and acquiring appropriate resources, these advisory boards can also serve as an effective mechanism for transferring best practices and 'lessons learned' from industry to academics. In this paper, the roles and responsibilities of several advisory boards constituted within the engineering school will be described to show how such boards are being effectively used for program development and management.

\section{Introduction}

Advisory boards are frequently found in academic institutions, including in engineering colleges, departments, and programs. And while many boards have similar-sounding charters and objectives, their effectiveness can vary widely. A random sampling of a few dozen engineering websites and colleges revealed the following characteristics:

- Advisory boards are most commonly used at the college or school level, although they are not uncommon at the department level. Individual program-level boards do exist but are relatively rare. Occasionally advisory boards are only organized at the institution level.

- Most boards meet twice per year; a few meet once, while a few others meet three or more times annually.

- The most frequent roles cited for advisory boards include assisting in identifying strategies, establishing priorities, advising on curricula and on developing resources.

- Although many boards perhaps make only minimal contributions, and perhaps their contributions are only minimally appreciated or utilized, this may well be due mostly to ineffective implementation rather than to planned marginalization. When boards are used to provide advice regarding curricula, it is most often with regards to the general nature of curricula of existing programs. This appears to be most common at the graduate program level, and, especially, with regard to prioritizing areas for research. In one instance, however, it was noted that an advisory board reviews details of "program educational objectives, and program outcomes, and offers suggestions for change to keep them current". (Santa Clara)

\section{Literature Review}


Genheimer and Shehab (2009) ${ }^{1}$, while reporting on a survey of engineering advisory boards' operations, and effectiveness, quote a 2002 study $^{2}$ that found a significant lack of data regarding interactions between engineering programs and advisory boards. They argue that this lack of detail remained essentially unchanged, by stating that "while the use of advisory boards to support engineering educational programs is common, there is relatively little written and no known comprehensive research on what it takes to establish and operate an effective advisory program." This paper appeared in April 2009, and a recent thorough search through EBSCO, LexisNexis Academic and ProQuest Databases indicates that this lack of data persists. Kaupins and $\mathrm{Coco}^{3}$ points out that "advisory boards bridge the gap between academic world and the workplace." However, poorly organized and run advisory boards may affect the performance of the school and programs 4 .

This paper does not purport to provide comprehensive research results on how to organize and maintain effective advisory boards. Rather, the intent is to report on demonstrated successes in utilizing advisory boards to dramatically improve the development and management of engineering and technology programs. The survey results from Genheimer and Shehab (2009) ${ }^{1}$ were from a subset of 38 large research engineering schools with well established alumni constituencies. By contrast, our results come from a master's level institution where the School of Engineering and Technology was only established in 2002, effectively eliminating the opportunity to select advisory board members from among the institution's well-to-do and well-established alumni (one of the strongest factors in predicting advisory board members' participation and contribution levels). This paper will also present results from a computer science program, where survey participation in one area was especially lacking.

In NU's SOET, it is now a common practice to organize a program advisory board whenever the development of a new program is being contemplated. In some early instances of program development, an advisory board was organized after the initial program development and launch was completed. The following sections of this paper will provide a summary description of our school-level advisory board, detailed examples of advisory board involvement, contributions for two programs where the boards were engaged concurrently with program development, and an additional two examples where the boards were organized subsequent to program launch. These programs include the following:

- Advisory boards organized prior to initiating program development

- BS Construction Management (CM)

- MS Cyber Security and Information Assurance (CSIA)

- Advisory boards organized subsequent to program development and launch

- MS Computer Science

○ MS Wireless Communications.

It can be noted that our practices align well with many of the "best practice" guidelines recommended by Olson (2008) for developing and maintaining engineering advisory boards. This includes such advice as personally inviting each potential board member, 
planning meetings months in advance in order to accommodate each member's busy schedules, holding meetings in respectable venues, using formal agendas, only planning on about $50 \%$ attendance at any one meeting (fortunately, we find that attendance is typically around $75 \%$ ), and offering other helpful recommendations.

\section{School of Engineering and Technology Advisory Board}

This school-level board has the following general guidelines for the duties and responsibilities of advisory board members:

- Be informed about the mission, values, programs and activities of the school;

- Help the school establish mutually beneficial partnerships with individuals, agencies, foundations, and corporations;

- Advise the school on strategic planning, program and curricula development, research initiatives and possibilities, and so forth;

- Review and provide input to SOET annual operating plans;

- Participate in the development and adoption of an annual plan for the Advisory Board;

- Recommend agenda items and any useful supporting materials prior to board meetings;

- Attend board meetings twice per year;

- Recommend and/or form committees to address pertinent issues identified by the Advisory Board;

- Participate on subcommittees formed to address top SOET priorities;

- Represent the school to the community;

- Advise the school on occupational and career trends;

- Provide mechanism for feedback to administration from students and faculty;

- Prepare a report for the Dean and other university administrators on Advisory Board assessments and observations.

Membership in this school-level board is designed such that it represents a cross section of industries and organizations that drive employment, technology, and growth in our current environment. The intent is to provide balanced representation across a variety of important fields in order to garner the best possible input relative to marketplace trends and needs, emerging growth sectors, "game changing" technology advances, and similar factors driving the overall school perspective. Current membership is described in Table 1.

\begin{tabular}{|l|l|}
\hline \multicolumn{1}{|c|}{ Position } & \multicolumn{1}{c|}{ Company (Industry) } \\
\hline CEO, President & Bourdon Consulting (biotech testing and validation) \\
\hline CEO & Xelo.us, llc (leveraged buyouts, management buyouts) \\
\hline CEO, President & E-Band Communications (telecommunications) \\
\hline President (retired) & ISO, ANSI (standards institutes) \\
\hline President & Sapient Focus (intellectual property and strategy) \\
\hline President, CEO & San Diego North Economic Development Council \\
\hline Director, R\&D & SAS Institute (software) \\
\hline Sr. Vice President & Sony (electronics) \\
\hline Partner & La Jolla Science Applications (technology development) \\
\hline
\end{tabular}




\begin{tabular}{|l|l|}
\hline CEO & The Olen Group, LLC (technology consulting) \\
\hline Principal & Langston Associates (defense contracting consultants) \\
\hline Vice Chancellor & San Diego Community College District \\
\hline Vice President & SAIC (defense, technology) \\
\hline President, CEO & Novatel Wireless (telecommunications) \\
\hline President & Bingham Construction (commercial construction) \\
\hline Director, Avionics & Northrop Grumman (defense, aerospace) \\
\hline Sr. Vice President & Cubic Corporation (defense, telecommunications, systems) \\
\hline
\end{tabular}

Table 1: Current School Level Board Membership

This advisory group has, relative to program development and management, recommended areas for potential new program offerings (e.g., "green" engineering, security, sensing, applications programming, health information systems, test and evaluation, others) and desired characteristics for our graduates (e.g., project management expertise, team building skills, ability to 'fit' into organization, bias for sharing and collaboration, writing and presentation skills, adaptability and versatility, "systems" view and approach to problem solving, others). All of these (and many others) have been, or are being, implemented. These contributions are important in driving the high level direction and strategy of the school, but for the purposes of this paper it is more relevant to examine program-specific advisory boards.

\section{Advisory Board Formed After Program Launch: M.S. Wireless Communications} While some industry professionals were consulted during the development of a new master's degree in Wireless Communications, this was done informally and the inputs were not systematically incorporated. Following the first two years of the program's existence a program-specific advisory board was formed (2006), including the following individuals (selected due to a combination of in-depth technical expertise and industry awareness):

- Sr. Vice President, Motorola

- Vice President, Qualcomm

- Vice President, Qualcomm

- Vice President, Leap Wireless International and Cricket Communications

- Director, Nokia

- Chief Technical Officer, Novatel Wireless

- Associate, Accenture National Security Services (and early MSWC alum)

Since 2006 the following major changes - initiated and advanced by the advisory board have been made in the MSWC program:

1. Two major recommendations of the Advisory Committee were to establish a course on wireless economics and to establish a wireless communications laboratory. In 2007, the School of Engineering and Technology received a significant grant from the San Diego-headquartered wireless network operator, Cricket Communications, (arranged by an advisory board member) for establishing a Wireless Communications Laboratory. In 2008, a new course (WCM 612) entitled Current Topics in Wireless Economics was added, The 
content was developed by a faculty member and a board member who worked on it collaboratively.

2. The advisory board recommended that a Project Management course should be added as a core course. But, upon further examination, instead of a course addition, a program learning outcome on project management was added to the Masters Research Project Courses (WCM 611A\&B).

3. It was identified that all but one of the WCM 603 Course Learning Outcomes (CLOs) were being covered in other courses. After careful examination of all MSWC courses, the WCM603 course was eliminated.

4. WCM 610 dealing with $4^{\text {th }}$ Generation Wireless Systems technology was combined into an existing course (WCM 607) on $3^{\text {rd }}$ Generation Wireless Systems. The parts of the then existing course on $4^{\text {th }}$ Generation Wireless Systems dealing with economics were moved into the new wireless economics course (WCM 612).

\section{Advisory Board Formed After Program Launch: M.S. Computer Science}

The master's program in Computer Science was developed in 2003, again with informally orchestrated inputs from external experts, but a formal advisory board was not organized until 2008. Examples of the value provided by this formal advisory board to the ongoing updating and management of the MSCS program come from the implementation of two important recommendations made at a board meeting in March, 2009.

1. It was reported that industry executives (including those represented on the board) were having difficulty finding computer science graduates with skills appropriate for the industry. In particular, graduates of local public and private universities were too focused on writing code or revising code, rather than on solving problems.. This opinion was summarized in the following statement: "They don't know how to really analyze problems and turn them into solutions" The board recommended revising our Program Learning Outcomes (PLOs) to reemphasize critical thinking skills and to include the ability for "researching" (i.e., analyzing and designing solutions for) problems in specific computer science disciplines. The board's recommendations and guidance, now reflected in all seven of the revised PLOs, are as follows. Upon successful completion of the program students will be able to

a. Create software requirements specifications, and design and develop complex software systems using software engineering processes and tools.

b. Evaluate computer security vulnerabilities and threats, and design effective and ethical countermeasures to address them

c. Analyze, design, and develop database solutions by translating database modeling theory into sound database design and implementation.

d. Analyze and design complex front-end applications for cloud and clientserver architectures and integrate them with backend databases.

e. Compare \& contrast alternative systems for process and memory management.

f. Demonstrate ability to conduct in-depth research, both individually as well as in teams, in a specific computer science area, as well as the ability to maintain currency in computer science through lifelong learning 
g. Demonstrate critical thinking skills as well as the ability to analyze and synthesize computer science concepts and skills while maintaining high ethical standards through graduate-level evaluative and creative written assignments and oral reports.

2. At the time of this meeting the School of Engineering and Technology offered three related master's degree programs: M.S. Computer Science, M.S. Database Administration, and M.S. Software Engineering. Enrollments were small in each program, as there were many similar courses between programs. Also, since all three programs related to different aspects of software development and utilization, students were frequently confused as to which program would best fit their needs. The Advisory Board endorsed a plan for consolidating these three programs into a single program with three areas of specialization. The resultant consolidation was published in the September 2009 catalog. The consolidated M.S. Computer Science program begins with all students taking a common set of six courses which offered them exposure to important fundamentals and principles in all three areas of software development and utilization. Students could, therefore, choose among three areas of specialization (each containing four courses): Advanced Computing, Database Engineering, or Software Engineering. After taking the core courses, students gained a much better understanding of the various options available to them in the field of computing and a much better idea of where their main interests lay. After completing the specialization courses students all come together for two master's project courses, where they experience solving real world software development challenges by working in teams that include members having different areas of specialization. This results in a multi-disciplinary (or multi-specialization) team experience which closely simulates 'real world' situations; this further enhances the objectives of the PLOs toward developing problem-solving abilities.

\section{Advisory Board Formed Prior to Program Development: B.S. Construction Management}

The university administration was approached by several construction industry executives who expressed an urgent need for "home grown" (i.e., from Southern California) graduates in construction management. Without appropriate programs at local universities, many companies were recruiting qualified construction management graduates from as far away as Texas and the Mid-West. . The primary problem with this approach to recruiting was the difficulty local companies were having in retaining new hires. Some specific reasons were the long distances between Southern California and the graduates' homes and families, and the very high cost-of-living (particularly housing) compared with Texas and Mid-West markets. In response to this input, it was determined that the university explores the development of a B.S. Construction Management program. The first step was to organize an advisory board of construction management executives and educational experts. This board included the following:

- CEO, Pacific Rim Mechanical

- President, Roel Construction

- Vice President, BNG Consultants

- Executive Vice President, Berg Electric 
- (then) President, Construction Management Association of America

- Vice President, Harris Associates

- Professor, Purdue University

Local executives had repeatedly cited the Purdue program as a model that produced capable graduates, so a key member of the Purdue faculty was included on the advisory board. Rather than merely duplicating the Purdue curriculum, the advisory board advocated a similar approach but with several significant additions and modifications. SOET faculty control and guidance ensured that the programs included rigorous treatment of foundational elements, while advisory group inputs were incorporated to ensure that the program learning outcomes also included elements essential for graduates being successful in the marketplace and in their professions. In response to important advisory board inputs, we included the following courses in program management; construction accounting, finance and legal issues; and design and construction process integration. The course learning outcomes for these courses were principally derived from advisory group input. With some minimal updating, including recommendations from advisory board members and other external reviewers, the program remains highly popular and successful as can be seen from the increase in student enrollment and employment success of graduates.

\section{Advisory Board Formed Prior to Program Development: M.S. Cyber Security and Information Assurance}

This is the newest of the above programs, being announced in the Fall 2010 catalog with the first classes set to begin in February, 2011. Because of the complex and vital nature of this subject in almost all areas, development of this program also entailed organization of our largest advisory board to-date. Board members include the following:

iNetwork Inc.

Cubic Corporation

Unisys

Idaho State University

Booz Allen Hamilton

VMware, Inc.

Serco

Association of IT Professionals

Unisys

The Computer Network Defense

Group LLC

Scripps Health

SGIS

ITT Communications Systems

Blade Systems Alliance

Sun Microsystems/Oracle
Vice President

Senior Vice President

Technology Evangelist

Associate Dean

Associate

CTO

Project Director

Association President

Regional Executive

CEO

Chief Information Security Officer

CEO

Director

President

Regional Manager 
Cubic Corporation

Lockheed Martin

Federal Bureau of Investigation

The Security Network

SPAWAR Space and Warfare

Systems

National Security Agency

Scripps Health

SAIC

SAIC

Computer Science Corporation

Cisco Systems

Blade Systems Alliance

SPAWAR

ISSA

AITP

Intel

Unisys

SMART Development

International

ESET, Securing Our eCity

SPADA Innovations
Vice President, CIO

Senior Manager

Supervisory Special Agent -- San Diego

President

Vice President, Information Assurance and

Technical Authority

Former Deputy Director

Director, Information Security Assurance

Vice President, Systems Engineering

Associate Vice President and Chief Engineer

Enterprise Technologist

Security Business Manager

Executive Director

Information Assurance National Lead

Chapter President

Association President

Regional Manager

Director, Global Stealth Solutions

CEO

Director

Business Development Manager

The first step in developing this new program was to determine what specific outcomes would be desirable. Identifying potential outcomes in this case was simplified by two sets of criteria. The first set comes from the National Security Agency (NSA), where they have identified standards for academic content - established by the Committee on National Security Systems - that must be present if a program is to become recognized as an NSA Center of Academic Excellence. An independent and widely recognized industry certification, the Certified Information Systems and Security Professional (CISSP), has identified 10 domains of required learning and capability. Combining the CNSS and CISSP standards yielded an initial list of desired program learning outcomes.

This list was next presented to the advisory board, and board members were asked to identify priority PLOs pertinent to their particular industries. Also, they were asked to define additional outcomes desirable in their particular industry segments. Opportunity was given for board members to provide individual feedback, and there was also an open discussion session dedicated to this topic in an advisory board meeting (held quarterly). Board members come from a variety of backgrounds representing industry segments from defense to communications, from law enforcement to hardware manufacturers, and 
from software to healthcare. Not surprisingly, therefore, responses identified a number of different priorities for PLOs. Extensive analysis of results allowed for PLOs to be grouped into five separate areas, all having a common set of underlying fundamental outcomes. Faculty proposed, and the board accepted, a proposal to develop the program around the core of common desired outcomes, with five specializations each containing one set of the industry-specific PLOs. This is the final structure approved for offering : a core of seven courses taken regardless of specialization, followed by a five course specialization in one of the following areas.

- Health Information Assurance

- Information Assurance and Security

- Cryptography Engineering

- Security Software Engineering

- Computer Forensics

Each specialization has a small subset of specific PLOs to be achieved for that particular specialization. All PLOs were developed in conjunct with the advisory board although faculty retained control and responsibility for ensuring that PLOs were complete, appropriate, and measurable. Advisory board members were also engaged during the next step of organizing outcomes and content into specific courses, each with defined course learning outcomes (CLOs). The result was a curriculum which combined meeting the needs of a variety of industry and market segments with the need for academic rigor, control and assessment.

Following completion of the curricula, advisory board members helped to publicize the new program through notices in organizational newsletters, announcements at meetings, and circulating program details among co-workers and through human resource organizations in their companies. The result of this recruiting assistance is a full initial cohort beginning February 2011.

The current stage of advisory board involvement is in assisting with the development of a companion CSIA research initiative; such a research initiative is also required of programs desiring NSA-CAE certification. Although the kick-off for developing this research activity was not planned to occur for another year, strong support and encouragement by the advisory board greatly accelerated initiation of this effort. The initial vision for this research initiative is to organize around a CSIA Institute comprised of multiple centers; each interested organization could establish their own center within the Institute, or join with other participants in a collaborative center. Board members have already come forward with plans to fund centers around security in cloud computing; certification/validation of proposed new security hardware or software; biometrics, and others. The University would probably not have been able to generate such rapid initiation and growth of research activity without having an engaged, influential and committed advisory board.

Assessing effectiveness of advisory board 
A number of methods can be used in assessing the effectiveness of advisory boards. It may vary from school to school. However, a few general rules of thumb can be used to assess the effectiveness of advisory board. They include:

- Effectiveness of program and/or associated changes

- Increase in admission

- Student employment changes

- External accreditation success

\section{Conclusion}

Program-specific advisory boards have been employed to assist and support the development and management of academic programs. The examples provided above demonstrate that advisory boards have been effective in such areas as identifying marketplace segments where additional educated graduates are needed, defining desirable learning outcomes at both the overall program and individual course levels, providing specific direction for revising and redesigning existing programs to meet the changing needs of industries and technologies, and acquiring resources to equip laboratories and to support new research initiatives. Membership on these boards is based on technical expertise, awareness of market conditions and needs, and ability to exert influence within a community or organization. Advisory boards, comprised of such members and given specific objectives, have definitely proven their worth here in National University's School of Engineering and Technology, and will, undoubtedly, continue to be valuable contributors to program development and management well into the future.

\section{References}

1. Genheimer, S.R. and Shehab, R.L."A Survey of Industry Advisory Board Operation and Effectiveness in Engineering Education," Journal of Engineering Education, 98, 2, Apr 2009, pp.169-180.

2. Rooney, D.M. and Puerzer, R.J. "The smaller Engineering school and Its Industrial Advisory Board: An Effective Partnership?," Frontiers in Education Annual Meeting, Boston, MA. 2002.

3. Kaupins, G. and Coco, M.”Administrator Perceptions of Business School Advisory Boards", Education, 123, 2, pp. 351-357.

4. Tummala, R.L. Personal Communication (2011)

5. Olson, G. A. "The Importance of External Advisory Boards," Chronicle of Higher Education, Vol. 54 Issue 24 (2008), 2-3. 